\title{
Mapping QTLs for resistance to Northern Leaf Blight in Tropical Maize (Zea mays L.)
}

\author{
Shridhar Hegde ${ }^{1 *}$, M. Kumar ${ }^{2}$, Mahantesh Gangashetti ${ }^{3}$ and N. Meenakshi Ganesan ${ }^{4}$ \\ ${ }^{1}$ Centre for Plant Breeding and Genetics, Tamil Nadu Agricultural University, \\ Coimbatore, Tamil Nadu, India \\ ${ }^{2}$ Department of cotton, Tamil Nadu Agricultural University, Coimbatore, Tamil Nadu, India \\ ${ }^{3}$ Directorate of Research, Tamil Nadu Agricultural University, Coimbatore, Tamilnadu, India \\ ${ }^{4}$ Pioneer Hi-Bred Pvt. Ltd., Kallinayakanahalli 561 213, Gauribidanur, Chikkaballapur, \\ Karnataka, India \\ *Corresponding author
}

\section{A B S T R A C T}

Northern Corn Leaf Blight (NCLB or NLB) caused by Exserohilum turcicum is a common disease of maize in many parts of the world including India. Resistance to NCLB is complexly inherited and controlled by several quantitative trait loci (QTL) distributed across the genome. Phenotype as well as linked DNA marker based selection for resistance to NCLB is expected to be effective. Hence an investigation was carried out involving a total of $569 \mathrm{~F}_{2: 3}$ families derived from two crosses viz., PH234 X PHBP3 and PH234 X PH84K, where PH234 is resistant parent and PHBP3 and PH84K are susceptible parents. During rainy 2016 and 2017 seasons, these $F_{3}$ progenies were screened for their reaction to NLB. Characterization of QTLs affecting resistance to NLB was undertaken using the genetic linkage map with polymorphic SNP marker loci and the phenotypic data of $F_{2: 3}$ families. Total five QTLs conferring resistance to NLB were identified which were spread on chromosomes 2, 3, 4, 7 and 10. While the QTL on chromosome 7 was more consistent, others were less consistent. Phenotypic variation explained by these QTLs varied from 3\% to $16 \%$. The detection of more than one QTL supports the hypothesis that quantitative genes control resistance to Exserohilumturcicum.

\section{Introduction}

Maize (Zea mays L.) is one of the most important cereal crops of the world and contributes to food security in most of the developing countries. In India, maize is emerging as the third most important crop after rice and wheat. Its importance lies in the fact that it is not only used for human food and animal feed, but at the same time, it is also widely used for corn starch industry, corn oil production, baby corns etc.

One of the major factors limiting the productivity of maize in the tropical Asian region is the increased incidence of insect pests and diseases. Among the various maize diseases, Northern Corn Leaf Blight (NCLB), 
caused by the pathogen Exserohilum turcicum is a serious threat to maize cultivation worldwide, reportedly causing yield losses of more than 50\% (Raymundo and Hooker 1981 and Perkins and Pederson 1987). NCLB is common in areas that have high humidity combined with moderate temperatures in the northeastern United States, in sub-Saharan Africa and in areas of China, Latin America, and India (Adipala et al., 1995 and Dingerdissen et al., 1996). In India, the disease is prevalent in Karnataka, Andhra Pradesh, Tamil Nadu, Bihar, Himachal Pradesh, Maharashtra and other regions (Harlapur et al., 2000).

Resistance to NCLB is complexly inherited and controlled by several quantitative trait loci (QTL) distributed across the genome. Phenotype as well as linked DNA marker based selection for resistance to NCLB is expected to be effective. Studies on resistance to NCLB point to a complex genetic architecture with many quantitative trait loci (QTL) distributed throughout the genome (Inghelandt et al., 2012 and Poland et al., 2011). Quantitative trait loci (QTL) for NCLB resistance have been identified from several populations (Brewster et al., 1992; Dingerdissen et al., 1996; Schechert et al., 1999; Welz and Geiger, 2000; Welz et al., 1999; Wisser et al., 2008 and Balint-Kurti et al., 2010) and are distributed throughout the genome (Wisser et al., 2006). In the present study, an attempt was made to validate these QTLs and identify novel QTLs using $\mathrm{F}_{2: 3}$ mappingpopulations derived from two half- sib populations.

\section{Materials and Methods}

Parent material and phenotyping of $F_{2: 3}$ mapping population for NLB

The mapping populations for the study were derived two crosses after initial evaluation of parental lines. The two crosses were PH234 X PHBP3 and PH234 X PH84Khaving 271 and $298 \mathrm{~F}_{3}$ progenies respectively. Among the parental lines, $\mathrm{PH} 234$ is tolerant and PHBP3 and $\mathrm{PH} 84 \mathrm{~K}$ are susceptible ones. $\mathrm{F}_{3}$ mapping populations were evaluated during rainy 2016 and 2017 in NLB hotspot near Hassan, Karnataka (lat. $13^{0} 09^{\prime} \mathrm{N}$ and long. $76^{\circ} 02^{\prime} \mathrm{E}$ ). The experiments consisting of $\mathrm{F}_{3}$ progenies along with parental lines were planted in Randomized complete design with two replications. Row length of 3 meter with row to row distance 0.6 meter and plant to plant distance $20 \mathrm{~cm}$ was uniformly adopted. Appropriate susceptible checks for northern corn leaf blight were sown after every 10th row to increase the disease pressure as well as to serve as spreader rows. To ensure uniform disease infestation, artificial inoculation was done by following the procedure detailed by Shekhar and Kumar (2012). Artificial inoculation was made 20 days after sowing between 3.00 to $6.00 \mathrm{PM}$ and inoculation was repeated one week after first inoculation. The northern corn leaf blight severity was recorded at dough stage i.e., 85 days after sowing by visualizing the leaf area using 1-9 scale (Ribeiro et al., 2016, www.pioneer.com), according to lesion spot development in the middle to upper part of leaves on a scale from 1 (Susceptible) to 9 (Resistant) thereby providing for a total of nine classes or categories where score 9: 0-5\% leaf loss, score 8: 6-10\% leaf loss, score 7: 11-24\% leaf loss, score 6: 25-44\% leaf loss, score 5: 45-55\% leaf loss, score 4: 56-66\% leaf loss, score 3: 67-77\% leaf loss, score 2: 78-88\% leaf loss and score 1: 89-100 leaf loss.

\section{SNP genotyping protocol}

Genotyping was performed on the individual samples by Pioneer Hi-Bred International (Johnston, IA), using a 90-markermultiplex assay on the Illumina (San Diego) Bead Array platform (Jones et al., 2009). 


\section{QTL analysis and mapping}

The analysis of QTLs controlling the northern corn leaf blight resistance was performed using the means of $F_{2: 3}$ family replicates for score data within each season and within families as well as across seasons and across families. The phenotypic data (Rainy 2016 and Rainy 2017) and genotypic data of 90 SNP markers across 10 chromosomes (which were imputed to 3315 markers) were subjected for constructing linkage map in order to identify the QTLs associated with the trait using proprietary software of Dupont Pioneer. LOD scores equal and more than 3.0 were used as threshold for significance testing of the existence of a QTL effect.

\section{Results and Discussion}

A total of $569 \mathrm{~F}_{2: 3}$ progeny families derived from two crosses were evaluated for their reactions to NLB during the rainy seasons of 2016 and 2017 at Hassan, Karnataka. Frequency distribution of $\mathrm{F}_{2: 3}$ progenies showed continuous variation in both populations and environments with clear transgressive segregation indicating quantitative resistance to NLB (Fig. 1).The ANOVA revealed significant differences among $\mathrm{F}_{2: 3}$ families in both the populations and seasons for disease incidence. However, since Levene's Test for Homogeneity reveled significant difference in NLB incidence over two seasons, across year pooled analysis was not done. This difference in NLB severity across seasons emphasizes the effect of environmental conditions on the occurrence of this disease.

\section{Genetic linkage map}

A total of 873 out of 3315 imputed SNP markers which showed expected 1:2:1 ratio as tested by chi-square test were used to construct a linkage map form $271 \mathrm{~F}_{2: 3}$ families from population 1 (Table 1) and 1102 out of 3315 markers were used for $298 \mathrm{~F}_{2: 3}$ families from population 2 (Table 2). The per cent polymorphism between the two parents used for developing mapping population as revealed by SNP markers were 23.3 and 33.24 in populations 1 and 2 respectively.

Table.1 Summary of complete marker data per chromosome and polymorphic markers for the population PH234 X PHBP3 (Pop 1)

\begin{tabular}{|c|c|c|c|c|c|}
\hline & $\begin{array}{c}\text { Complete markers data per } \\
\text { Chromosome }\end{array}$ & \multicolumn{3}{|c|}{ Polymorphic SNP markers } & \\
\hline Chromosome & SNPs & Length & SNPs & Length & $\begin{array}{c}\text { Parental } \\
\text { polymorphism } \\
(\mathbf{\%})=\mathbf{2 3 . 3 3}\end{array}$ \\
\hline Ch1 & 569 & 322 & 155 & 318.51 \\
\hline Ch2 & 428 & 257 & 110 & 253.45 & \\
\hline Ch3 & 299 & 251 & 70 & 246.42 & \\
\hline Ch4 & 276 & 248 & 67 & 246.31 \\
\hline Ch5 & 346 & 228 & 101 & 223.55 \\
\hline Ch6 & 287 & 184 & 82 & 180.79 \\
\hline Ch7 & 268 & 214 & 69 & 205.52 \\
\hline Ch8 & 331 & 213 & 94 & 206.56 \\
\hline Ch9 & 257 & 185 & 62 & 174.92 \\
\hline Ch10 & 254 & 164 & 63 & 154.88 \\
\hline Total & $\mathbf{3 3 1 5}$ & $\mathbf{2 2 6 6}$ & $\mathbf{8 7 3}$ & $\mathbf{2 2 1 0 . 9 1}$ & \\
\hline
\end{tabular}


Table.2 Summary of complete marker data per chromosome and polymorphic markers for the population PH234 X PH84K (Pop 2)

\begin{tabular}{|c|c|c|c|c|c|}
\hline & \multicolumn{2}{|c|}{$\begin{array}{c}\text { Complete markers data per } \\
\text { Chromosome }\end{array}$} & Polymorphic SNP markers & \\
\hline Chromosome & SNPs & Length(cM) & SNPs & Length(cM) & $\begin{array}{c}\text { Parental } \\
\text { polymorphism } \\
\text { (\%)=33.24 }\end{array}$ \\
\hline Ch1 & 569 & 322 & 185 & 317.23 & 252.75 \\
\hline Ch2 & 428 & 257 & 138 & 246.42 \\
\hline Ch3 & 299 & 251 & 98 & 246.31 \\
\hline Ch4 & 276 & 248 & 82 & 226.8 \\
\hline Ch5 & 346 & 228 & 113 & 180.79 \\
\hline Ch6 & 287 & 184 & 112 & 205.29 \\
\hline Ch7 & 268 & 214 & 95 & 210.31 \\
\hline Ch8 & 331 & 213 & 107 & 181.19 \\
\hline Ch9 & 257 & 185 & 82 & 159.23 \\
\hline Ch10 & 254 & 164 & 90 & $\mathbf{2 2 2 6 . 3 2}$ \\
\hline Total & $\mathbf{3 3 1 5}$ & $\mathbf{2 2 6 6}$ & $\mathbf{1 1 0 2}$ & \\
\hline
\end{tabular}

Table.3 QTLs detected for NLB resistance in individual populations for both the seasons

\begin{tabular}{|c|c|c|c|c|c|c|c|c|c|c|}
\hline \multirow[t]{2}{*}{ Population } & \multicolumn{5}{|c|}{ Kharif 2016} & \multicolumn{5}{|c|}{ Kharif 2017} \\
\hline & Chr. & Pos. & LOD & $\mathbf{N}$ & $\begin{array}{c}\mathbf{R}^{2} \\
(\%)\end{array}$ & Chr. & Pos. & LOD & $\mathbf{N}$ & $\begin{array}{c}\mathbf{R}^{2} \\
(\%)\end{array}$ \\
\hline \multirow{3}{*}{$\begin{array}{c}\text { PH234 X PHBP3 } \\
\text { (Pop1) }\end{array}$} & 7 & 85.2 & 9.3 & 271 & 12 & 7 & 79 & 2.1 & 271 & 5 \\
\hline & & & & & & 2 & 175 & 6.6 & 271 & 9 \\
\hline & & & & & & 10 & 118 & 5.4 & 271 & 6 \\
\hline \multirow{3}{*}{$\begin{array}{c}\text { PH234 X PH84K } \\
\text { (Pop2) }\end{array}$} & 3 & 104 & 13.2 & 298 & 16 & 3 & 102 & 11.2 & 298 & 12 \\
\hline & 4 & 178 & 6.7 & 298 & 7 & 4 & 154 & 6.2 & 298 & 6 \\
\hline & & & & & & 7 & 94 & 9.7 & 298 & 10 \\
\hline \multirow{2}{*}{$\begin{array}{l}\text { Pooled Analysis } \\
\text { (Pop1 \& Pop2) }\end{array}$} & 7 & 87 & 15 & 569 & 9 & 3 & 115.4 & 3.4 & 569 & 3 \\
\hline & & & & & & 7 & 94 & 5.4 & 569 & 16 \\
\hline
\end{tabular}


Fig.1 Frequency distribution of $\mathrm{F}_{3}$ progenies of the cross PH234 X PHBP3 (Pop 1) and PH234 X PH84K (Pop 2)

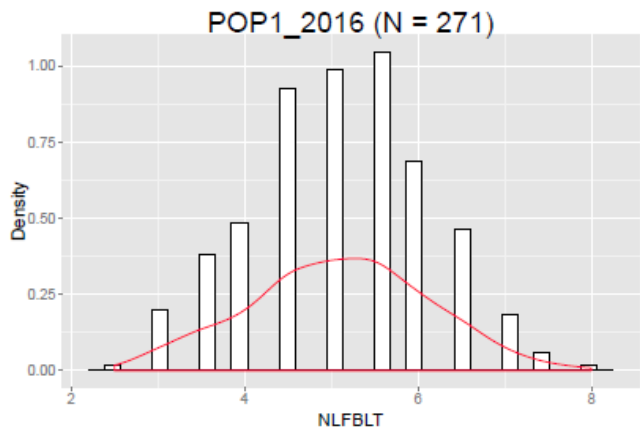

Mean $=5.09$, Std. Dev=1.03, N=271

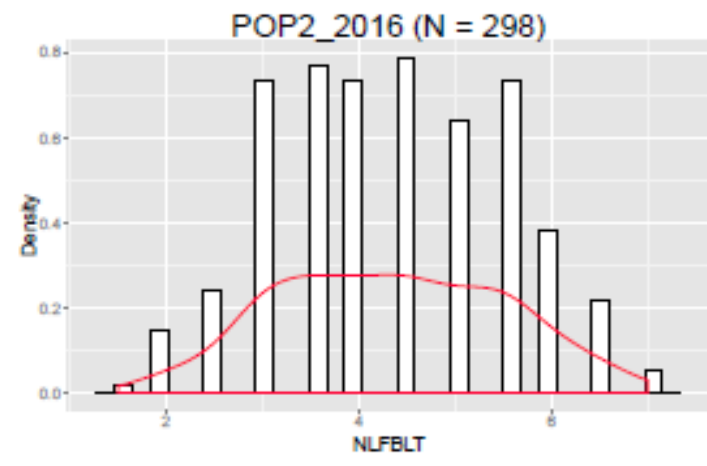

Mean $=4.33$, Std. Dev $=1.17, \mathrm{~N}=298$

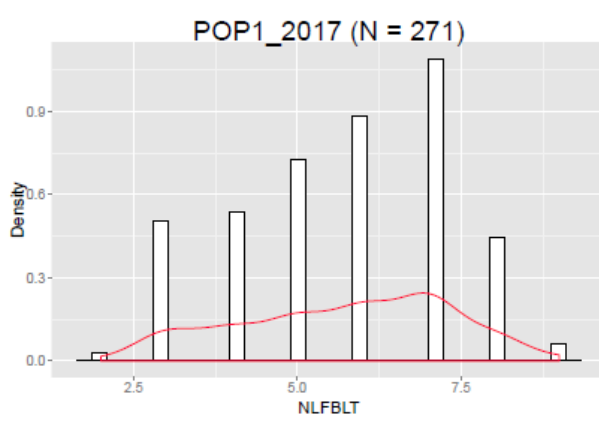

Mean= 5.7, Std.Dev= 1.6, N=271

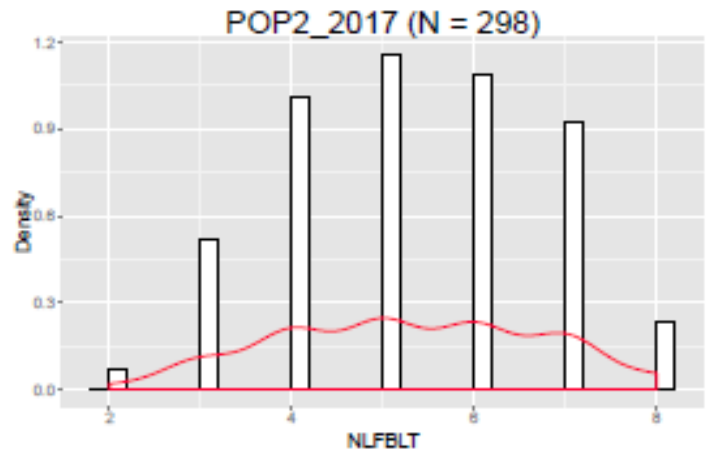

Mean $=5.28$, Std. Dev=1.43, N=298

Fig.2 LOD peaks (-log 10p) for NLB for detected QTLs in two populations during rainy 2016 and rainy 2017. Horizontal solid line indicates threshold LOD score
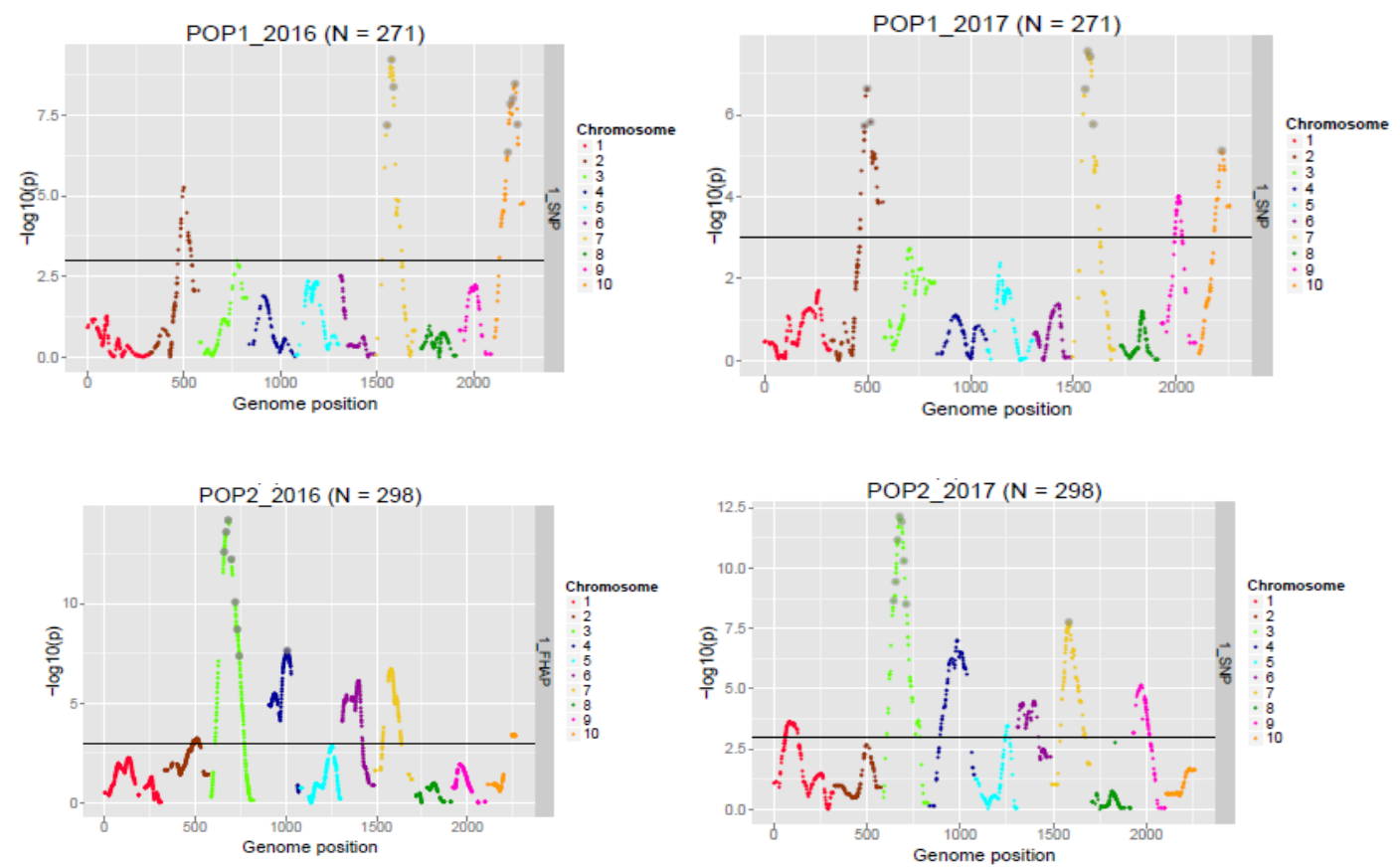
QTL analysis for NLB resistance in $F_{2: 3}$ mapping population

QTLs were considered to be significant when the LOD scores exceed the threshold 3.0. Major and minor QTLs were classified with percentage of phenotypic variation $\left(\mathrm{R}^{2}\right)$ more than 10.0 as major QTL and QTL with $\mathrm{R}^{2}$ less than 10.0 as minor QTL. Three QTL regions associated with NLB resistance were largely distributed over three chromosomes (chromosomes 3, 4 and 7) (Table 3 and Fig. 2). In population 1, one significant QTL was found on chromosome 7 when 2016 data was analyzed with LOD score of 9.3 and a phenotypic variation of $12 \%$ (Table 3 ). However, by using 2017 data, a nonsignificant QTL was found on the same chromosome in the same vicinity with $5 \%$ phenotypic variation while, two more significant QTLs were identified; one each on chromosome 2 and 10 with phenotypic variation of $9 \%$ and $6 \%$ respectively. In population 2, two significant QTLs were found using 2016 data, one each on chromosome 3 and 4 with LOD scores of 13.2 and 6.7 respectively with $\mathrm{R}^{2}$ values of $16 \%$ and $7 \%$ respectively. Whereas, using 2017 data of population 2, three significant QTLs were identified, each one on chromosomes 3 , 4 and 7 with LOD scores of 11.2, 6.2, 9.7 respectively explaining a phenotypic variation of $12 \%, 6 \%$ and $10 \%$ respectively. In the year-wise pooled analysis of two populations with $569 \mathrm{~F}_{2: 3}$ families, one significant QTL with LOD of 15 and phenotypic variance of 9 \% was found on chromosome 7 in 2016. Similar result was observed using 2017 data also with significant QTL on the same chromosome (chr.7) with LOD of 5.4 and phenotypic variation $16 \%$. The lack of commonality between the QTLs identified in different populations could be attributed to combination of various factors viz., the type and size of the mapping population used, segregation of different sets of QTLs in different crosses, detection of QTLs in a segregating population only if both parental lines contributed different alleles of the QTL and epistatic interaction between QTLs in different mapping populations (Beavis and Keim, 1996 and Bohn et al., 1997). Beavis et al., (1991) recorded that a comparison of data for QTL localization in various segregating populations for disease resistance reveals only a few QTLs that are common across populations. This is particularly relevant because of the fact that different climatic and growing conditions at each environment might affect the expression of QTL involved in developmental, morphological and biochemical characters affecting resistance against specific pathogen. However, reasonably consistent major QTL identified in this study on chromosome 7 could be good resource for breeding NLB resistance into tropical maize lines using MAS.

\section{References}

Adipala, E., Takan, J. P. and Ogenga-Latigo, M. W., 1995, Effect of planting density of maize on the progress and spread of Northern leaf blight from Exserohilum turcicum infested residue source. Europ. J. Plant Pathol., 101: 25-33.

Balint-kurti, P. J., Yang, J., Esbroeck, G. V., Jung, J. and Smith, M. E., 2010, Use of a maize advanced intercross line for mapping of QTL for Northern leaf blight resistance and multiple disease resistance. Crop Sci., 50: 458-466.

Beavis WD, Grant D, Albertsen MC, Fincher RR (1991) Quantitative trait loci for plant height in four maize populations and their associations with qualitative genetic loci. TheorAppl Genet 83(2):141-145

Beavis WD, Keim P (1996) Identification of quantitative trait locithat are affected by environment. In: Kang MS, Gauch Jr HG(eds) Genotype by environment interaction. CRC Press, BocaRaton, pp. 123-149

Bohn M, Khairallah MM, Jiang CZ, Gonzalez de Leon D,Hoisington D, Utz HF, Deutsch JA, 
Jewell DC, Mihm JA, Melchinger AE (1997) QTL mapping in tropical maize. 2. Comparison of genomic regions for resistance to Diatraeaspp. Crop Sci 37(6):1892-1902

Brewster, V. A., Carson, M. L. and Wicks, Z. W., 1992, Mapping components of partial resistance to northern leaf blight of maize using reciprocal translocations. Phytopathol., 82: 225-229.

Dingerdissen, A. L., Geiger, H. H., Lee, M., Schechert, A. and Welz, H. G., 1996, Interval mapping of genes for quantitative resistance of maize to Setosphaeriaturcica, cause of northern leaf blight, in a tropical environment. Mol. Breed., 2: 143-156.

Harlapur S. I., Wali M. C., Anahosur K. H. and Muralikrishna. 2000. Survey and surveillance of maize diseases in North Karnataka. Karnataka J.Agric. Sci., 13(3): 750-751.

Inghelandt, V. D., Melchinger, A. E., Martinant, J. P. and Stich, B., 2012 Genome-wide association mapping of flowering time and northern corn leaf blight (Setosphaeriaturcica) resistance in a vast commercial maize germplasm set. Plant Biology, 12: 56-70.

Jones E, Chu WC, Ayele M, Ho J, Bruggeman E, Yourstone K, Rafalski A, Smith OS, McMullen MD, Bezawada C, Warren J, Babayev J, Basu S, Smith S (2009) Development of singlenucleotide polymorphism (SNP) markers for use in commercial maize (Zea mays L.). Mol Breed. 24:165-176

Perkins, J. M., and W. L. Pederson, 1987 Disease development and yield losses associated with northern corn leaf blight on corn. Plant Dis. 71:940-943.
Poland, J. A., Bradbury, P. J., Buckler, E. S. and Nelson, R. J., 2011, Genome-wide nested association mapping of quantitative resistance to northern leaf blight in maize. Proc. Natl. Acad. Sci., 108: 6893-6898.

Raymundo, A. D., and A. L. Hooker, 1981. Measuring the relationship between northern corn leaf blight and yield losses. Plant Dis. 65: 325-327.

Ribeiro R.M., do Amaral, A.T., Pena, G.F., Vivas, M., Kurosawa, R.N. and Goncalves, L.S.A., 2016. History of northern corn leaf blight disease in the seventh cycle of recurrent selection of an UENF-14 popcorn population. ActaScientiarum, Argon., 38(4): 447-455.

Schechert, A. L., Welz, H. G. and Geiger, H. H., 1999, QTL for resistance to Setosphaeriaturcica in tropical African maize. Crop Sci., 39: 514-523.

Shekhar M. and Kumar S. 2012. Inoculation methods and disease rating scales for maize diseases. In: Directorate of Maize, ICAR, New Delhi, 2-16.

Welz, H. G. and Geiger, H. H., 2000, Genes for resistance to northern corn leaf blight in diverse maize populations. Plant Breed., 119: 1-14.

Welz, H. G., Xia, X. C., Bassett I, P., Melchinger, A. E. and Lubberstedt, T., 1999, QTLs for resistance to Setosphaeriaturcica in an early maturing dent $\times$ flint maize population. Theor. Appl. Genet., 99: 649655

Wisser, R., Nelson, R., Kolkman, J., Walsh, E., Smith, M., Yang, J. and Balint-kurti, P., 2008, Multiple Disease Resistance in Maize. Poster Presented at the 50th Annual Maize Genetics Conference, 27th Feb to 2nd March, 2008 Washington DC, USA, pp. 1.

\section{How to cite this article:}

Shridhar Hegde, M. Kumar, Mahantesh Gangashetti and N. Meenakshi Ganesan. 2018. Mapping QTLs for resistance to Northern Leaf Blight in Tropical Maize (Zea mays L.). Int.J.Curr.Microbiol.App.Sci. 7(06): 1940-1946. doi: https://doi.org/10.20546/ijcmas.2018.706.230 